\title{
Twin Studies on Obsessive-Compulsive Disorder: A Review
}

\author{
Daniël S. van Grootheest, ${ }^{1,2}$ Daniëlle C. Cath, ${ }^{2}$ Aartjan T. Beekman, ${ }^{2}$ and Dorret I. Boomsma \\ ' Department of Biological Psychology, Vrije Universiteit Amsterdam, Amsterdam, the Netherlands \\ ${ }^{2}$ Department of Psychiatry, Vrije Universiteit Amsterdam, Amsterdam, the Netherlands
}

G enetic factors have historically been thought of as important in the development of obsessive-compulsive disorder (OCD). For the estimation of the relative importance of genetic and environmental factors, twin studies are an obvious approach. Twin studies of OCD have a long history, starting in 1929. In this review, over 70 years of twin research of OCD is presented, using four different approaches that represent the steps in the twin research of OCD from past to present. These steps include (1) case-studies of twins with OCD from the old literature; (2) twin studies of OCD using Diagnostic and Statistical Manual of Mental Disorders (DSM) criteria; (3) twin studies of OCD using a dimensional approach, comparing resemblances in monozygotic and dizygotic twins; and (4) twin studies of OCD using a dimensional approach, analyzing the data with Structural Equation Modeling. It is concluded that only the studies using the last method have convincingly shown that, in children, obsessive-compulsive (OC) symptoms are heritable, with genetic influences in the range of $45 \%$ to $65 \%$. In adults, studies are suggestive for a genetic influence on OC symptoms, ranging from $27 \%$ to $47 \%$, but a large twin study using a biometrical approach with continuous data is still needed to provide conclusive evidence. Strategies for future twin studies of OCD are discussed.

Obsessive-compulsive disorder (OCD) is a psychiatric disorder characterized by intrusive, unwanted thoughts, fears and images (obsessions) on the one hand and/or repetitive ritualized behavior or mental acts (compulsions) on the other hand (American Psychiatric Association, 1994). Compulsions are usually performed to relieve the anxiety and/or distress caused by the obsessions. The most frequent types of obsessions are fear of contamination, pathological doubt, somatic obsessions, need for symmetry, and sexual and aggressive obsessions. Well-known compulsions are checking, washing, counting, symmetry/precision and hoarding. Obsessive-compulsive (OC) symptoms are remarkably diverse and the clinical presentation can vary both within and across patients over time (Leckman et al., 1997). Nowadays, many studies have provided strong evidence that OCD is not a unitary nosological entity, as suggested by the current concept of Diagnostic and Statistical Manual of Mental Disorders (4th ed.; DSMIV; American Psychiatric Association, 1994), but a clinically heterogeneous disorder (Miguel et al., 2005). Patients experience a chronic or episodic course with exacerbations that can substantially impair social, occupational and academic functioning (Nestadt et al., 2000). The lifetime prevalence of OCD is estimated between $0.7 \%$ and $2.5 \%$ (Horwath \& Weissman, 2000). Family studies of OCD have suggested that OCD is familial (Grados et al., 2003), which is not synonymous with heritable. Genetic-epidemiological methods to study the relative roles played by genes and environment in the etiology of OCD include twin and adoption studies. Adoption studies are generally rare, and to our knowledge no such studies have been published on OCD. Twin studies are based on the fact that monozygotic (MZ) twins are genetically identical, while dizygotic (DZ) twins share on average $50 \%$ of their segregating genes, which is similar to any nontwin siblings. If $\mathrm{MZ}$ twins resemble each other more than DZ twins, this is indicative for the importance of genetic influences on the trait under consideration. The influence of genetic factors has been suggested from the earliest descriptions of the disorder until the present (Pauls \& Alsobrook, 1999), but the twin studies literature on OCD has never been reviewed extensively, apart from some attention in book chapters (Billett et al., 1998; Macdonald et al., 1991). In this review, whether twin studies on OCD indeed suggest that OCD is a heritable disorder is addressed by giving an overview of all reported twin studies of OCD in the literature. We begin with case studies from the old literature and end with more recent twin studies using a model-fitting approach. Finally, we draw conclusions about the heritability of OCD and discuss new strategies for future twin studies on OCD.

Received 24 May, 2005; accepted 1 June, 2005.

Address for correspondence: Daniël van Grootheest, Vrije Universiteit, Department of Biological Psychology, Van der Boechorststraat 1, 1081 BT Amsterdam, the Netherlands.E-mail: Ds.van.grootheest@psy.vu.nl 
Table 1

Case Studies of Twins With OCD in the Old Literature

\begin{tabular}{|c|c|c|c|c|c|}
\hline Study & $\begin{array}{l}\text { No. of } \\
\text { twin pairs }\end{array}$ & $\begin{array}{l}\text { Zygosity determination } \\
\text { supported }\end{array}$ & $\begin{array}{l}\mathrm{MZ} \\
\mathrm{C} / \mathrm{D}\end{array}$ & $\begin{array}{l}D Z \\
C / D\end{array}$ & Diagnostic information \\
\hline Lange (1929) & 3 & No & $1 / 2$ & & $\begin{array}{l}\text { 'Obsessional symptoms' - one MZ } \\
\text { twin with brain damage }\end{array}$ \\
\hline Le Gras $(1932,1933)$ & 1 & No & $1 / 0$ & & 'Hysteria with Obsessional symptoms' \\
\hline Lewis (1935) & 3 & No & $2 / 1$ & & 'Obsessional illness' — one pair with ОСР \\
\hline Tarozzi (1939) & 1 & No & $1 / 0$ & & 'Psychoneurosis with obsessional ideas' \\
\hline Rüdin (1953) & 1 & No & & $0 / 1$ & ‘Obsessional neurosis' \\
\hline Tienari (1963) & 11 & No & $10 / 1$ & & $\begin{array}{l}\text { 'Phobic or obsessional neurosis' - mix } \\
\text { of OC features, traits and syndromes }\end{array}$ \\
\hline Parker (1964) & 2 & Yes & $0 / 2$ & & 'Obsessional neurosis' \\
\hline Woodruff \& Pitts (1964) & 1 & Yes & $1 / 0$ & & ‘Obsessional behavior' \\
\hline Inouye (1965; Ihda, 1965) & 14 & No & $8 / 2$ & $1 / 3$ & $\begin{array}{l}\text { ‘Obsessive-compulsive reaction’ - } \\
\text { one case likely Tourette's syndrome }\end{array}$ \\
\hline
\end{tabular}

Note: $\mathrm{MZ}=$ monozygotic twins; $\mathrm{DZ}=$ dizygotic twins; $\mathrm{C} / \mathrm{D}=$ concordant/discordant; $\mathrm{OCP}=$ obsessive-compulsive personality disorder; $\mathrm{OC}=$ obsessive-compulsive.

\section{Case Studies of Twins With OCD in the Old Literature, 1929-1965}

In 1929, Lange published the first cases of twins with OCD in an article on the pathology of twins in psychiatry (Lange, 1929). This paper marked the beginning of twin studies on OCD. An overview of all published case studies of twins with OCD in the old literature, published between 1929 and 1965, is presented in Table 1.

Most studies of this era have failed to distinguish between OC neurosis and mixed neurosis, and showed a tendency to confuse OC neurosis with OC personality or obsessive traits (Hoaken \& Schnurr, 1980). The history of OCD can partly explain this observation. In 1878, Westphal considered genetics to represent the most prominent etiological factor in OCD (Westphal, 1878). OCD was at that time a clearly defined psychiatric disorder, thought to be caused by organic factors such as a dysfunction of the autonomic nervous system. Largely based on the ideas of Freud (1896), this view of OCD changed and by the second half of the 20th century OCD was (1) separated into obsessive neurosis and obsessive personality disorder; (2) considered to be on a continuum, ranging from 'normal' neurotic behavior, through personality disorder to neurosis, which warranted psychotherapy; (3) thought to be largely caused by early traumatic experiences or environmental factors; and (4) governed by psychoanalytic theories (Denys, 2004). Clear definitions of obsessive neurosis or obsessive personality disorder did not exist and this is reflected in the different diagnostic information provided by the case studies. Most studies provide insufficient clinical data to verify a diagnosis of OCD, severely hampering judgment on whether the subjects would meet current standardized diagnostic criteria (Billett et al., 1998). Moreover, comparison of the case studies is difficult due to differences in diagnostic criteria between studies. Furthermore, there seemed to be a tendency to publish MZ and concordant twins, introducing reporting bias. This bias is caused by collecting twins in an unsystematic way, which tends to favor $\mathrm{MZ}$ and concordant pairs (Clifford et al., 1984). Another problem with case studies was mentioned by Lewis (1935), who wrote that 'a striking concordance in one or two pairs of $\mathrm{MZ}$ twins proves nothing: one needs a series and control group of fraternal twins'. It is interesting, however, that Woodruff and Pitts (1964) regarded even one set of $\mathrm{MZ}$ twins concordant for obsessional illness as important, stating that it was statistically improbable for MZ twins to be concordant in the absence of common determinants. This conclusion was based on their frequently cited calculation of the prevalence of OCD as $0.05 \%$ of the general population (Woodruff \& Pitts, 1964). They wrote that one in 132 live births are $\mathrm{MZ}$ twins and calculated that the chance of finding a pair of $M Z$ adult twins where both had OCD would be one in 600 million if the disorder would arise independently in each co-twin and was not due to some combination of shared genetic or environmental factors.

The twin rule of pathology, that is, any heritable disease will be more concordant in identical twins than in nonidentical twins, was already formulated in 1924 (Siemens). But around 1960 the debate continued as to which conclusions could be drawn from the finding of a markedly increased concordance of $\mathrm{MZ}$ 
compared to DZ twins in schizophrenia (Parker, 1964). Besides the conclusion that a genetic predisposition could exist, an exclusive environmental basis for this consistent finding was also proposed (Jackson, 1960). This environmental basis could be caused by close identification or by confusion of ego identity, which was suggested to occur in MZ twins (Jackson, 1960). Rosenthal (1960) had already shown that the second factor could not be held responsible, as twins in general would then be expected to have a higher incidence of schizophrenia than the general population, which is not the case. Parker (1964) described two MZ twins discordant for OCD, attempting to illustrate with these cases that marked identification can still occur without both twins developing symptoms of neurotic illness, throwing doubt on the validity of this purely environmental theory.

A further limitation of the old literature is the lack of any procedural blind to obtain diagnostic information or establish diagnoses. Knowledge of an index case's status while evaluating the co-twin or vice versa is an unacceptable source of bias (Pauls \& Alsobrook, 1999). Finally, in many cases the method of zygosity determination is unclear or there is lack of information to definitively establish monozygosity. With these limitations in mind, no conclusions on the heritability of OCD can be drawn from this literature.

\section{Twin Studies of OCD Meeting DSM Criteria}

The development of the Diagnostic and Statistical Manual of Mental Disorders (3rd ed.; DSM-III; American Psychiatric Association, 1980) meant a new step forward in psychiatric research. Disorders in DSM-III have been defined in terms of syndromes, that is, symptoms that are observed in clinical populations to co-vary together in individuals. The major advantage of adopting a descriptive classification was its improved reliability over prior classification systems using nonoperationalized definitions of disorders. From the outset, however, it was recognized that the primary strength of this descriptive approach was its ability to improve communication among clinicians and researchers, not its established validity (Kupfer et al., 2002).

Table 2 shows several case studies and four larger epidemiological twin studies on OCD, meeting DSM-III or DSM-III-R (3rd ed., rev.; American Psychiatric Association, 1987) criteria. The standardization of the diagnosis and higher reliability of the zygosity determination diminish some limitations of the case studies described above. Although case studies of twins with OCD can hardly solve the question about heritability, they can inspire researchers by generating new hypotheses, which can be a starting point for subsequent research. For example, McKeon et al. (1984) described

\section{Table 2}

Twin Studies of OCD Meeting DSM-III or DSM-III-R Criteria

\begin{tabular}{|c|c|c|c|c|}
\hline Study & $\begin{array}{c}\text { No. of } \\
\text { twin pairs }\end{array}$ & $\begin{array}{l}M Z \\
C / D\end{array}$ & $\begin{array}{l}D Z \\
C / D\end{array}$ & Diagnostic information \\
\hline Marks et al. (1969) & 1 & $1 / 0$ & & \\
\hline Tarsh (1978) & 1 & & $1 / 0$ & Both twins improved after leucotomy \\
\hline Hoaken \& Schurr (1980) & 1 & $0 / 1$ & & \\
\hline McGuffin \& Mawson (1980) & 2 & $2 / 0$ & & \\
\hline Carey \& Gottesman (1981) & 30 & $13 / 2$ & $7 / 8$ & \\
\hline Torgersen (1983) & 12 & $0 / 3$ & $0 / 9$ & \\
\hline McKeon et al. (1984) & 1 & $0 / 1$ & & OCD after head injury \\
\hline Mahgroub et al. (1988) & 1 & $1 / 0$ & & $\begin{array}{l}\text { First-born twin also has epilepsy } \\
\text { Second-born twin minor OC symptoms }\end{array}$ \\
\hline Kim et al. (1990) & 1 & $1 / 0$ & & \\
\hline Andrews et al. (1990) & 48 & $0 / 18$ & $0 / 30$ & \\
\hline Lewis et al. (1991) & 3 & $3 / 0$ & & $\begin{array}{l}\text { All three twin pairs disconcordant for } \\
\text { schizophrenia/schizoaffective disorder }\end{array}$ \\
\hline Cryan et al. (1992) & 1 & $1 / 0$ & & $\begin{array}{l}\text { Both concordant for } O C D \text { and paraphilia } \\
\text { (twin part of triplet) }\end{array}$ \\
\hline Skre et al. (1993) & 8 & $5 *$ & $0 / 3$ & \\
\hline
\end{tabular}


four cases of OC neurosis following head injury, one from a discordant $\mathrm{MZ}$ twin pair. The twin is a 23-yearold Ugandan immigrant who started having OC symptoms after he was knocked down by a car and was unconscious for 10 days. His rituals involved repeated checking of his clothing, brushing his teeth for more than an hour at a time and taking extensive precautions to avoid contamination in the bathroom. His early development had been normal and closely similar to that of his co-twin, who had at no period in his development exhibited OC symptoms. However, following the head injury, the twin's behavior became clearly discordant from his brothers. The authors conclude that head injury is a probable contributor to the development of OC neurosis in some cases.

Four epidemiologic studies were published that will be described more extensively. Carey and Gottesman (1981) selected 30 twin pairs, $15 \mathrm{MZ}$ and 15 DZ, from the Maudsley Twin Register, which represents a consecutive series of patients who were admitted to the Maudsley or Bethlem hospitals between 1948 and 1979. All probands reported unequivocal obsessional symptoms according to DSM-III criteria. The diagnosis may have been secondary to another diagnosis, so the results apply to obsessional symptoms that occurred both on their own and in addition to other psychiatric disorders. Concordance rates for 'obsessive symptoms or features with or without treatment' were $87 \%$ for MZ pairs and $47 \%$ for DZ pairs. Concordance rates for an 'episode of psychiatric or GP treatment involving obsessional symptoms' were $33 \%$ for MZ pairs and $7 \%$ (one twin pair) for $\mathrm{DZ}$ pairs.

Torgersen (1983) investigated genetic factors in the determination of six anxiety disorders in a study of 32 $\mathrm{MZ}$ and $53 \mathrm{DZ}$ adult same-sex twin pairs from Norway. The sample consisted of twins born between 1910 and 1955 who were admitted for the treatment of neurotic or borderline psychotic disorder prior to 1977. Each twin was diagnosed according to DSM-III criteria. Of the 85 probands, 12 twins, three $\mathrm{MZ}$ and nine DZ, had an OCD, but no co-twins with OCD were found. Although no twins were found to be concordant for any of the other DSM anxiety disorders either, the author examined concordance rates in the larger context of an 'anxiety spectrum' (Pauls \& Alsobrook, 1999). When the sexes were combined, the concordance for anxiety disorders in the proband group labeled 'all anxiety disorders without general anxiety disorder (GAD)' was $45 \%$ in $\mathrm{MZ}$ pairs to $15 \%$ in DZ pairs. The author concludes that genetic factors appear to influence the development of anxiety disorders in general, with the exception of GAD.

Andrews et al. (1990) administered structured psychiatric interviews on DSM-III criteria, the Composite International Diagnostic Interview (CIDI), to $186 \mathrm{MZ}$ and $260 \mathrm{DZ}$ twin pairs, culled from the Australian Twin Registry. Lifetime diagnoses for major depressive disorder, dysthymia, GAD, OCD, panic disorder, social phobia and agoraphobia with panic were obtained. In total, 48 twins with a diagnosis of OCD were reported, but no concordant twin pairs with OCD were found. Although there was a genetic contribution to neuroticism and to symptoms of depression and anxiety, no inheritance of any specific disorders was found.

Skre et al. (1993) performed a twin study of DSMIII-R anxiety disorders in 81 same-sex twin pairs. The sample of twin probands consisted of twins with nonpsychotic disorders and was ascertained from several subsamples of twins in Norway. One subsample overlapped with the sample used in the study of Torgersen (Torgersen, 1983). In the anxiety disorder proband group containing $20 \mathrm{MZ}$ and $29 \mathrm{DZ}$ twins, three MZ twins and two DZ twins were found to have OCD. In the co-twin group of the anxiety probands, two MZ twins with OCD were found but it is not clear in the article if these are concordant $\mathrm{MZ}$ twins or not. In the co-twins of the comparison group with probands having no anxiety disorder at all, another DZ twin with OCD was found. The authors conclude that their results do not contribute to a clarification of the etiology of OCD.

Several important aspects may limit the interpretation of these epidemiologic studies. Although the use of DSM-III or DSM-III-R criteria reduces the risk of false positive diagnoses, the failure to use separate interviewers for each member of a twin pair with each interviewer blind to the zygosity status of the pair introduces a large potential for inadvertent bias in the detection of illness (Pauls \& Alsobrook, 1999). Torgersen (1983) and Andrews et al. (1990) combined different diagnostic categories to determine concordance rates. Although both groups of investigators argue that the results support the notion that there are common genetic factors for at least some anxiety disorders, by combining across diagnoses, both groups could have been capitalizing on chance (Pauls \& Alsobrook, 1999). Lastly, in population-based samples, the low prevalence of DSM-diagnosed OCD generally will lead to low statistical power to ascribe the familial clustering of OCD to either shared genes or shared environment.

\section{Twin Studies of OCD Using a Dimensional Approach, Comparing Resemblances in MZ and DZ Twins}

The classical twin method compares phenotypic resemblances between $\mathrm{MZ}$ and $\mathrm{DZ}$ twins. Comparing the resemblance of $M Z$ twins for a trait or disease with the resemblance of $\mathrm{DZ}$ twins offers an estimate of the extent to which genetic variation determines phenotypic variation of that trait: the heritability ( $\mathrm{h}^{2}$; Boomsma et al., 2002). The classical twin method allows the use of categorical data like diagnoses but also continuously distributed traits, such as obsessional trait or symptom scores, in twins. Macdonald et al. (1991) recommended that instead 
Table 3

Twin Studies of OCD Using a Dimensional Approach, Comparing Resemblances in MZ and DZ Twins

\begin{tabular}{lcll}
\hline \multicolumn{1}{c}{ Study } & No. of twin pairs & Sample characteristics & Diagnostic information \\
\hline Young et al. (1971) & 32 & Only men, cross-sectional data & $\begin{array}{l}\text { Obsessional traits and symptoms } \\
\text { according to a subscale of the } \\
\text { Middlesex Hospital Questionnaire }\end{array}$ \\
Torgersen (1980) & 99 & Men and women, cross-sectional data & $\begin{array}{l}\text { Obsessional traits according to } \\
\text { the Lazar et al. questionnaire }\end{array}$ \\
Clifford et al. (1984) & 419 & Men and women, cross-sectional data & $\begin{array}{l}\text { OC symptoms according to the } \\
\text { Leyton Obsessional Inventory }\end{array}$ \\
\hline
\end{tabular}

Note: $\mathrm{OC}$ = obsessive-compulsive.

of relating diagnoses to thresholds on an underlying liability distribution, we should aim for measures that are more direct indices of this liability distribution and hence examine the genetic and environmental basis of individual differences in vulnerability to develop clinically significant OCD. $\mathrm{OCD}$ is in this case viewed as the equivalent of extreme scores on symptom or trait measures. Such a dimensional approach removes the problem of scarcity of twins with the full disease and also removes the need for population-based prevalence rates for comparison.

Young et al. (1971) were the first researchers to apply a dimensional approach to OCD, using OC symptoms (Table 3 ). They conducted a small study of 17 pairs of identical male twins and 15 pairs of fraternal twins to examine the inheritance of neurotic traits. The 32 twin pairs completed the Middlesex Hospital Questionnaire, which contains a brief obsessional traits and symptoms subscale. Comparison of the intraclass correlations between the two twin series did not reveal a significant difference on the obsessional subscale score.

Torgersen (1980) examined 99 same-sex pairs of twins, $22 \mathrm{MZ}$ female, $28 \mathrm{MZ}$ male, $27 \mathrm{DZ}$ female and $22 \mathrm{DZ}$ male twin pairs. Eleven pairs were selected on the basis of hospitalization of one of the twins for neurotic problems. The remaining pairs were derived from the folk register of two cities to represent twin pairs from the general population. Torgersen compared intrapair variations of an obsessive personality factor, but did not find a significant difference between the MZ and DZ twins. The heritability of the obsessive scale was .18 for men and .23 for women. Torgersen hypothesized that in our society, a possible genetic core may perhaps be masked by the overwhelming environmental influences. It is difficult to evaluate the significance of these findings because of low statistical power and the biased ascertainment of twins. Furthermore, the obsessional scale used measured persistent personality traits rather than state dependent repetitive behavior (Macdonald et al., 1991).

The paper of Clifford et al. (1984) marked the beginning of research on quantitative traits in relatively large samples of twins from the normal population, measuring OCD using standardized instruments and with a promising dimensional approach. Clifford et al. were well aware of the disadvantages of case studies and stated that if obsessional neurosis is regarded as a distinct disease entity qualitatively different from normal behavior, then it is almost impossible to devise ways of examining any possible etiological role for heredity. However, a more contemporary view of the neuroses considers them as conditions to which individuals towards the extreme ends of normally distributed symptom or trait dimensions are especially prone'. A sample of 419 twins participated, with a bias towards female and MZ twins. Obsessionality was measured using a 42-item version of the Leyton Obsessional Inventory (Cooper, 1970). It contained 10 items of the trait scale and 32 items of the symptom scale. The heritability estimates for obsessional traits and symptoms were $44 \%$ and $47 \%$ respectively. No effect of common environment was found, thus unique environment explained the remaining variation. Multivariate analysis revealed two genetic factors of obsessionality, one factor related to a general trait of neuroticism and most strongly related to incompleteness and gloomy thoughts. The second genetic factor was related to checking and cleanliness. Finally, considerable hereditary variation appeared to be specific to each of the four factors.

\section{Twin Studies of OCD Using a Dimensional Approach, Analyzing the Data With Structural Equation Modeling}

The quantitative traits that have been assessed in $M Z$ and DZ twins have traditionally been analyzed using analysis of variance and intraclass correlations to summarize twin resemblances (Boomsma et al., 2002). However, this approach cannot accommodate the effect of sex on variances and covariance within and between twin pairs, nor can results easily be extended to multivariate and longitudinal data. Structural Equation Modeling (SEM), also known as covariance modeling, is a more general alternative approach, in which genotypic and environmental effects are 
Table 4

Twin Studies of OCD Using a Dimensional Approach, Analyzing the Data with Structural Equation Modeling

\begin{tabular}{|c|c|c|c|}
\hline Study & No. of twin pairs & Sample characteristics & Diagnostic information \\
\hline Jonnal et al. (2000) & 527 & $\begin{array}{l}\text { Only women, } \\
\text { cross-sectional data }\end{array}$ & $\begin{array}{l}\text { OC symptoms according to } 20 \\
\text { items of the Padua Inventory }\end{array}$ \\
\hline Eley et al. (2003) & 4564 & $\begin{array}{l}\text { Children aged } 4 \text { years, } \\
\text { cross-sectional data }\end{array}$ & $\begin{array}{l}\text { OC behavior according to a } \\
\text { 4-item } O C \text { scale }\end{array}$ \\
\hline Hudziak et al. (2004) & 4246 & $\begin{array}{l}\text { Children aged } 7,10 \text { and } 12 \text { years, } \\
\text { longitudinal data }\end{array}$ & $\begin{array}{l}\text { OC symptoms according to an } \\
\text { 8-item OC scale contained in the } \\
\text { Child Behavior Checklist }\end{array}$ \\
\hline
\end{tabular}

Note: $\mathrm{OC}=$ obsessive-compulsive.

modeled as the contribution of unmeasured (latent) variables to the potentially multivariate phenotypic differences between individuals (Neale \& Cardon, 1992).

Jonnal et al. (2000) used this approach in a twin study of OCD, examining 527 pairs of female twins using 20 items of the Padua Inventory (Sanavio, 1988; Table 4). The sample consisted of 334 female MZ twins and 193 pairs of DZ twins from the Virginia Twin Registry. A principal component analysis on the 20 items showed a two-factor solution that divided the items into a compulsiveness factor and an obsessiveness factor. By using SEM, the best-fit model suggested heritabilities of $33 \%$ and $26 \%$ for obsessiveness and compulsiveness respectively. Unique environmental effects accounted for $67 \%$ and $74 \%$ of the variance. The correlation between additive genetic effects on obsessiveness and compulsiveness was .53. The main conclusion was that self-report symptoms of obsessions and compulsions in women in the general population are moderately heritable and partly due to the same genetic risk factors. They also tested the equal environment assumption (EEA). Twin studies assume that $\mathrm{MZ}$ and $\mathrm{DZ}$ twin pairs are equally correlated for the exposure to environmental factors of etiologic relevance to the trait under study. No environmental effects that could be affecting the heritability were found and it was concluded that the EEA was not violated. Jonnal et al. (2000) noted three potentially important methodological limitations. First, they only selected a subset of items from the Padua Inventory, reducing the ability to detect a more complex and stable structure and increasing error variance. In a cross-sectional design, error variance cannot be distinguished from individual-specific environment with an underestimation of the impact of genetic factors as a result. Second, the study included only women, so conclusions cannot be generalized to men. Third, the data exhibited a pronounced right skew, although similar heritability estimates were produced after correction.

Eley et al. (2003) examined the phenotypic differentiation and genetics of mother-reported anxiety-related behaviors in 4564 4-year-old twin pairs from a population-based twin study, the Twins Early Development Study. Parents completed a 16-item questionnaire on anxiety-related behaviors in young children. The items were selected to assess five dimensions, including OC behavior (four items). For OC behavior there was substantial genetic influence with a heritability estimate of $65 \%$ and a $35 \%$ estimate of nonshared environment. Small negative sibling interaction effects were found, indicating rater-contrast or sibling competition effects.

Recently Hudziak et al. (2004) examined 4246 twin pairs of the Netherlands Twin Register (NTR) and 1461 twin pairs from the Missouri Twin Study Sample (MOTWIN). The 4246 twin pairs of the NTR were aged 7 years, of whom 2841 were reexamined at age 10 and 1562 were reexamined at age 12 . The participants of MOTWIN were a mixed-age group with an average age of 9 years. An 8-item Obsessive-Compulsive Scale (OCS) was used from the Child Behavior Checklist (CBCL; Achenbach, 1991). The scale was validated in a clinical sample of children with OCD based on DSM-IV criteria and showed adequate predictive value (Nelson et al., 2001). Across age groups and cultures, the best fitting model indicated additive genetic influences of the CBCL OCS score between $45 \%$ and $61 \%$, and unique environmental influences between $42 \%$ and $55 \%$. Only the NTR sample aged 12 years showed shared environmental influences of $16 \%$. Minor sex differences were seen in the mixed-age MOTWIN twins only. No evidence of dominance, sibling interaction, or rater-contrast effects was seen.

Because of the age of the study sample, both Eley et al. (2003) and Hudziak et al. (2004) had to rely on parent reports, which may be influenced by characteristics of the rater.

\section{Conclusion}

Although the first twin report was written on OCD in 1929 , it was not until 50 years later that Clifford et al. (1984) suggested genetic effects on obsessional symptoms, particularly cleanliness and checking. This study showed a first clear indication for the heritability of OC symptoms, moreover displaying a foreseeing notion of the multidimensionality of OCD. Although earlier twin studies have sometimes suggested the role of genes in OCD, several limitations diminish the utility of this literature (Billett et al., 1998; Black, 1974). Therefore both Macdonald et al. (1991) and 
Pauls and Alsobrook (1999) concluded that due to the absence of twin studies to replicate the Clifford et al. findings, the effect size of genetic influences on OCD was still undetermined. Strikingly, 15 years lapsed after the publications of Clifford et al. before a second informative twin study on the heritability of OC symptomatology was published on female twins (Jonnal et al., 2000). However, in their review and meta-analysis of the genetic epidemiology of anxiety disorders, Hettema et al. (2001) could not find twin studies on OCD that met their inclusion criteria. These criteria for twin studies were the use of operationalized diagnostic criteria and systematic ascertainment of probands. Only recently is methodologically sound research emerging investigating the contribution of disease-specific and common underlying genetic makeup in the occurrence of OC symptoms in children (Eley et al., 2003; Hudziak et al., 2004).

In conclusion, twin studies of children provide support for the hypothesis that genetic factors play a significant role in OC manifestation. Twin studies of adults are indicative, but a large twin study using a biometrical approach with continuous data is needed to provide conclusive evidence.

\section{Future of Twin Studies and OCD}

Recent research on OCD has made clear that OCD appears to encompass a heterogeneous phenotype with at least four symptom dimensions (Mataix-Cols et al., 2005). This heterogeneity may obscure the findings of clinical, natural history and treatment response studies and complicates the search for vulnerability genes (Miguel et al., 2005). A better description of clinical phenotypes should facilitate genetic studies. In fact, dissecting the phenotype into less complex components may be an important tool in the identification of susceptibility genes in OCD. Miguel et al. (2005) suggested three possible approaches. First, narrowing the phenotype to identify categorically defined homogeneous and mutually exclusive subtypes of OCD such as tic-related OCD or early onset OCD. Second, considering $\mathrm{OC}$ symptom dimensions as quantitative components of the more complex OCD phenotype, such as cleaning or hoarding. Third, broadening the phenotype to include other etiologically related conditions, for example generalized anxiety disorders and OCD spectrum disorders (Hollander, 1993). A combined dimensional approach within distinctive subgroups is proposed as probably the most effective in helping to identify the heritable components of OCD. What can the twin design contribute to this approach?

The first step would be to replicate factor-analyzed OC-symptom dimensions in an epidemiological twin sample and to calculate heritabilities per symptom dimension. Parameters such as tic-relatedness or age at onset can be included. The twins who fall in a certain dimension and/or subgroup with high heritability can be further examined in linkage studies. By using this approach the identification of susceptibility genes for OCD may come closer to reality. This approach still uses the MZ-DZ comparison to estimate the contributions of genetic and environmental effects to phenotypic variance, in this case an OCD dimension. Extending the MZ-DZ design to include the testing of parents, siblings, spouses and offspring offers the opportunity to assess the presence of cultural transmission, genotype $\mathrm{X}$ environment covariance, nonrandom mating and social interactions within and between generations (Truett et al., 1994). Extended twin designs also enable assessment of the effect of age difference on heritability and assessment of differential gene expression as a function of age (Boomsma et al., 2002). One can imagine that partially different genes influence OC symptom levels and dimensions at different ages. This may be important information for gene-finding studies, as there may be a limited time period during which various genes engaged in OC symptoms over the course of an individual's life can be detected.

One step further is the use of multivariate analyses in which the causes of association and comorbidity between traits and genotype $\mathrm{X}$ environment interaction can be investigated (Boomsma et al., 2002). Multivariate twin studies enable research on questions such as: Does a certain OC symptom dimension increase the risk for another symptom dimension, or is there a common genetic vulnerability for both? In line with the third approach mentioned by Miguel et al. (2005), it might be fruitful to analyze the causes of comorbidity in a multivariate twin design and establish the extent to which symptom dimensions that cluster share a common genetic basis.

Another step to enhance the discriminative capacity of linkage and association studies in understanding the genetic basis of OCD would be to identify endophenotypes associated with OCD (Miguel et al., 2005). Endophenotypes are defined as measurable components unseen by the unaided eye along the pathway between disease and distal genotype (Gottesman \& Gould, 2003). At this moment, structural and functional neuroimaging studies are most promising to identify endophenotypes for OCD. If suitable endophenotypes can be found, multivariate analyses are needed for the simultaneous modeling of OC symptoms/dimensions and endophenotypes to determine their common genetic etiology.

If, at last, genes can be found for OCD, quantitative and molecular genetic methodology will be applied simultaneously to patients and controls, sib-pairs, twins, and so on to study the effects of genes in different environments or the impact of different therapeutic interventions in different genotypic groups (Sham, 2003). After more than 70 years of twin studies on OCD, a new chapter of twin studies on OCD is just beginning.

\section{Acknowledgments}

This research was supported by ZonMw, grant no. 920-03-268 and no. 400-03-330. 


\section{References}

Achenbach, T. M. (1991). Manual for the Child Behavior Checklist/4-18 and 1991 profile. Burlington, VT: University of Vermont, Department of Psychiatry.

American Psychiatric Association. (1980). Diagnostic and statistical manual of mental disorders (3rd ed.). Washington, DC: Author.

American Psychiatric Association. (1987). Diagnostic and statistical manual of mental disorders (3rd ed., rev.). Washington, DC: Author.

American Psychiatric Association. (1994). Diagnostic and statistical manual of mental disorders (4th ed.). Washington, DC: Author.

Andrews, G., Stewart, G., Allen, R., \& Henderson, A. S. (1990). The genetics of six neurotic disorders: A twin study. Journal of Affective Disorders, 19, 23-29.

Billett, E. A., Richter, M. A., \& Kennedy, J. L. (1998). Genetics of obsessive-compulsive disorder. In R. P. Swinson, M. M. Antony, S. Rachman, \& M. A. Richter (Eds.), Obsessive-compulsive disorder: Theory, research and treatment (pp. 181-206). New York: The Guilford Press.

Black, A. (1974). The natural history of obsessional neurosis. In H. T. Beech (Ed.), Obsessional states (pp. 19-54). London: Methuen.

Boomsma, D., Busjahn, A., \& Peltonen, L. (2002). Classical twin studies and beyond. Nature Reviews Genetics, 3, 872-882.

Carey, G., \& Gottesman, I. I. (1981). Twin and familiy studies of anxiety, phobic, and obsessive disorders. In D. F. Klein \& J. Rabkin (Eds.), Anxiety: New research and changing concepts (pp. 117-136). New York: Raven Press.

Clifford, C. A., Murray, R. M., \& Fulker, D. W. (1984). Genetic and environmental influences on obsessional traits and symptoms. Psychological Medicine, 14, 791-800.

Cooper, J. (1970). The Leyton obsessional inventory. Psychological Medicine, 1, 48-64.

Cryan, E. M., Butcher, G. J., \& Webb, M. G. (1992). Obsessive-compulsive disorder and paraphilia in a monozygotic twin pair. British Journal of Psychiatry, 161, 694-698.

Denys, D. (2004). On certainty. Studies in obsessive compulsive disorder. Utrecht, the Netherlands: UMC.

Eley, T. C., Bolton, D., O’Connor, T. G., Perrin, S., Smith, P., \& Plomin, R. (2003). A twin study of anxietyrelated behaviours in pre-school children. Journal of Child Psychology and Psychiatry and Allied Disciplines, 44, 945-960.

Freud, S. (1896). L'hérédité et l'étiologie des névroses [Heredity and the etiology of the neuroses]. In S. Freud, Névrose, psychose et perversion. Paris: Presses Universitaires de France.

Gottesman, I. I., \& Gould, T. D. (2003). The endophenotype concept in psychiatry: Etymology and strategic intentions. American Journal of Psychiatry, 160, 636-645.

Grados, M. A., Walkup, J., \& Walford, S. (2003). Genetics of obsessive-compulsive disorders: New findings and challenges. Brain and Development, 25(Suppl. 1), S55-S61.
Hettema, J. M., Neale, M. C., \& Kendler, K. S. (2001). A review and meta-analysis of the genetic epidemiology of anxiety disorders. American Journal of Psychiatry, $158,1568-1578$.

Hoaken, P. C., \& Schnurr, R. (1980). Genetic factors in obsessive-compulsive neurosis? A rare case of discordant monozygotic twins. Canadian Journal of Psychiatry, 25, 167-172.

Hollander, E. (1993). Obsessive-compulsive-related disorders. Washington, DC: American Psychiatric Press.

Horwath, E., \& Weissman, M. M. (2000). The epidemiology and cross-national presentation of obsessive-compulsive disorder. Psychiatric Clinics of North America, 23, 493-507.

Hudziak, J. J., van Beijsterveldt, C. E. M., Althoff, R. R., Stanger, C., Rettew, D. C., Nelson, E. C., Todd, R. D., Bartels, M., \& Boomsma, D. I. (2004). Genetic and environmental contributions to the Child Behavior Checklist Obsessive-Compulsive Scale: A cross-cultural twin study. Archives of General Psychiatry, 61, 608-616.

Ihda, S. (1965). Psychiatrische Zwillingsforschung in Japan [Psychiatric twin research in Japan]. Archiv fur Psychiatrie und Nervenkrankheiten, 207, 206-220.

Inouye, E. (1965). Similar and dissimilar manifestations of obsessive-compulsive neuroses in monozygotic twins. American Journal of Psychiatry, 121, 1171-1175.

Jackson, D. D. (1960). A critique of the literature on the genetics of schizophrenia. In D. D. Jackson (Ed.), Etiology of Schizophrenia. New York: Basic Books.

Jonnal, A. H., Gardner, C. O., Prescott, C. A., \& Kendler, K. S. (2000). Obsessive and compulsive symptoms in a general population sample of female twins. American Journal of Medical Genetics, 96, 791-796.

Kim, S. W., Dysken, M. W., \& Kline, M. D. (1990). Monozygotic twins with obsessive-compulsive disorder. British Journal of Psychiatry, 156, 435-438.

Kupfer, D. J., First, M. B., \& Regier, D. E. (2002). Introduction. In D. J. Kupfer, M. B. First, \& D. E. Regier (Eds.), A research agenda for DSM-V (pp. xv-xxiii). Washington, DC: American Psychiatric Association.

Lange, J. (1929). Leistungen der Zwillingpathologie für die Psychiatrie [The importance of twin pathology for psychiatry]. Allgemeine Zeitschrift für Psychiatrie und psychisch-gerichtliche Medicin, 90, 122-142.

Leckman, J. F., Grice, D. E., Boardman, J., Zhang, H., Vitale, A., Bondi, C., Alsobrook, J., Peterson, B. S., Cohen, D. J., Rasmussen, S. A., Goodman, W. K., McDougle, C. J., \& Pauls, D. L. (1997). Symptoms of obsessive-compulsive disorder. American Journal of Psychiatry, 154, 911-917.

Le Gras, A. M. (1932). Psychose en criminaliteit bij tweelingen [Psychosis and criminality in twins]. Unpublished doctoral dissertation, Rijksuniversiteit Utrecht, the Netherlands.

Le Gras, A. M. (1933). Psychose und Kriminalität bei Zwillingen [Psychosis and criminality in twins]. Zeitschrift für die gesamte Neurologie und Psychiatrie, 198-222.

Lewis, A. (1935). Problems of obsessional illness. Proceedings of the Royal Society of Medicine, XXIX, 325-336. 
Lewis, S. W., Chitkara, B., \& Reveley, A. M. (1991). Obsessive-compulsive disorder and schizophrenia in three identical twin pairs. Psychological Medicine, 21, $135-141$.

Macdonald, A. M., Murray, R. M., \& Clifford, C. A. (1991). The contribution of heredity to obsessional disorder and personality: A review of family and twin study evidence. In M. T. Tsuang, K. S. Kendler, \& M. J. Lyons (Eds.), Genetic issues in psychosocial epidemiology (pp. 191-212). New Brunswick, NJ: Rutgers University Press.

Mahgroub, O. M., Ahmed, M. A. M., \& Al-Suhaibani, M. O. (1988). Identical Saudi twins concordant for obsessive-compulsive disorder. Saudi Medical Journal, 9, 641-643.

Marks, I. M., Crowe, M., Drewe, E., Young, J., \& Dewhurst, W. G. (1969). Obsessive compulsive neurosis in identical twins. British Journal of Psychiatry, 115, 991-998.

Mataix-Cols, D., do Rosario-Campos, M. C., \& Leckman, J. F. (2005). A multidimensional model of obsessive-compulsive disorder. American Journal of Psychiatry, 162, 228-238.

McGuffin, P., \& Mawson, D. (1980). Obsessive-compulsive neurosis: Two identical twin pairs. British Journal of Psychiatry, 137, 285-287.

McKeon, J., McGuffin, P., \& Robinson, P. (1984). Obsessive-compulsive neurosis following head injury. A report of four cases. British Journal of Psychiatry, 144, 190-192.

Miguel, E. C., Leckman, J. F., Rauch, S., do RosarioCampos, M. C., Hounie, A. G., Mercadante, M. T., Chacon, P., \& Pauls, D. L. (2005). Obsessive-compulsive disorder phenotypes: Implications for genetic studies. Molecular Psychiatry, 10, 258-275.

Neale, M. C., \& Cardon, L. R. (1992). Methodology for genetic studies of twins and families. Dordrecht, the Netherlands: Kluwer Academic.

Nelson, E. C., Hanna, G. L., Hudziak, J. J., Botteron, K. N., Heath, A. C., \& Todd, R. D. (2001). Obsessive-compulsive scale of the child behavior checklist: Specificity, sensitivity, and predictive power. Pediatrics, 108, E14.

Nestadt, G., Samuels, J., Riddle, M., Bienvenu, O. J., III, Liang, K. Y., LaBuda, M., Walkup, J., Grados, M., \& Hoehn-Saric, R. (2000). A family study of obsessive-compulsive disorder. Archives of General Psychiatry, 57, 358-363.

Parker, N. (1964). Close identification in twins discordant for obsessional neurosis. British Journal of Psychiatry, 110, 496-504.

Pauls, D. L., \& Alsobrook, J. P. (1999). The inheritance of obsessive-compulsive disorder. Child and Adolescent Psychiatric Clinics of North America, 8, 481-96, viii.
Rosenthal, D. (1960). Confusion of identity and the frequency of schizophrenia in twins. Archives of General Psychiatry, 3, 297-304.

Rüdin, E. (1953). Ein Beitrag zur Frage der Zwangskrankheit, insbesondere ihrer hereditären beziehungen [A contribution to questions about obsessional illness, especially its heredity]. Archiv fur Psychiatrie und Nervenkrankheiten, 191, 14-54.

Sanavio, E. (1988). Obsessions and compulsions: The Padua Inventory. Behaviour Research and Therapy, 26, 169-177.

Sham, P. (2003). Recent developments in quantitative trait loci analyses. In R. Plomin, J. C. Defries, I. W. Craig, \& P. McGuffin (Eds.), Behavioral genetics in the postgenomic era (pp. 41-54). Washington, DC: American Psychological Association.

Siemens, H. W. (1924). Die Zwillingspathologie: Ihre Bedeutung, ihre Methodik, ibre bisherigen Ergebnisse [Twin pathology: Its meaning, its method and results so far]. Berlin, Germany: Springer.

Skre, I., Onstad, S., Torgersen, S., Lygren, S., \& Kringlen, E. (1993). A twin study of DSM-III-R anxiety disorders. Acta Psychiatrica Scandinavica, 88, 85-92.

Tarozzi, G. (1939). Über Zwillingspsychosen [About twin psychoses]. Zentralblatt für die Gesamte Neurologie und Psychiatrie, 92, 82.

Tarsh, M. J. (1978). Severe obsessional illness in dizygotic twins treated by leukotomy. Comprehensive Psychiatry, 19, 165-169.

Tienari, P. (1963). Psychiatric illnesses in identical twins. Acta Psychiatrica Scandinavica, 39(Suppl. 171), 1-195.

Torgersen, S. (1980). The oral, obsessive, and hysterical personality syndromes. A study of hereditary and environmental factors by means of the twin method. Archives of General Psychiatry, 37, 1272-1277.

Torgersen, S. (1983). Genetic factors in anxiety disorders. Archives of General Psychiatry, 40, 1085-1089.

Truett, K. R., Eaves, L. J., Walters, E. E., Heath, A. C., Hewitt, J. K., Meyer, J. M., Silberg, J., Neale, M. C., Martin, N. G., \& Kendler, K. S. (1994). A model system for analysis of family resemblance in extended kinships of twins. Behavior Genetics, 24, 35-49.

Westphal, C. (1878). Über zwangvorstellungen [About obsessions]. Archiv für psychiatrie und nervenkrankheiten, 734-760.

Woodruff, R., \& Pitts, F. N., Jr. (1964). Monozygotic twins with obsessional illness. American Journal of Psychiatry, 120, 1075-1080.

Young, J. P., Fenton, G. W., \& Lader, M. H. (1971). The inheritance of neurotic traits: A twin study of the Middlesex Hospital Questionnaire. British Journal of Psychiatry, 119, 393-398. 